\title{
Flexible Body Dynamics of the Goldfish C-Start: Implications for Reticulospinal Command Mechanisms
}

\author{
Robert C. Eaton, Randolf DiDomenico, and Jonathan Nissanova \\ Behavioral Neuroscience Group, Department of Biology, University of Colorado, Boulder, Colorado 80309
}

\begin{abstract}
As a model for learning how reticulospinal networks coordinate movement, we have analyzed the function of the Mauthner (M-) neurons in the escape response of the goldfish. We used water displacements of 3-6 $\mu \mathrm{m}$ to elicit C-start escape responses. These responses consist of 2 fundamental movements that grade into each other: Stage 1 lasts $15-40 \mathrm{msec}$ and rotates the body $30^{\circ}-100^{\circ}$ about the center of mass; stage 2 is an axial acceleration that moves the center of mass 2-6 cm. Combined, the 2 stages result in trajectory turns ranging from $15^{\circ}$ to $135^{\circ}$. Thus, these data show that $M$-initiated $C$-starts are not fixed movement patterns. The durations of stage 1 body muscle EMGs were correlated with turn angles achieved during stage 1 . Since variable stage 1 EMGs are not seen when the M-cell is triggered by itself, other circuits, independent of the M-cell, nust control the extent of the initial turn, and consequently escape trajectory. Furthermore, turning angles of stages 1 and 2 were correlated, allowing escape trajectory to be predicted, on average, $26 \mathrm{msec}$ after movement started. This suggests that the commands for escape trajectory should be organized by the end of stage 1 . In concert with this, the time of onset of the stage 2 EMG preceded the stage 2 onset by a range with a mean of $28.4 \mathrm{msec}$, typically putting the stage 2 command at the beginning of stage 1 movement. Thus, stage 2 initiation does not require motion-dependent feedback. Our findings indicate that the Mauthner cell initiates the first of a series of motor commands that establish the initial left-right decision of the escape sequence from the side of the stimulus, whereas parallel circuits simultaneously organize the command controlling the escape angle.
\end{abstract}

Comprehensive neural processing is required for motor activities such as orientation and locomotion that incorporate diverse muscles of the limbs and body. By imposing a kind of "hardwired coordination," the reticulospinal (RS) system is thought to play an essential role in the integration of such movements (Peterson, 1984). Beginning with Sprague and Chambers (1954),

\footnotetext{
Received June 3, 1987; revised Dec. 14, 1987; accepted Dec. 15, 1987.

We thank J. G. Canfield, M. B. Foreman, R. K. K. Lee, and P. W. Webb for comments on the manuscript, C. M. Wieland for technical assistance, and R. R. Fay for suggesting, prior to his own publication on the topic (Fay, 1984), the use of the displacement stimulus for this study. This work was supported by grants (to R. C. E.) from the National Institutes of Health (NS22621) and the National Science Foundation (BNS-12423) and NIH Grants BRSG RR07013-19 and RR07013-21 (Division of Research Resources) to the University of Colorado.

Correspondence should be addressed to Robert C. Eaton, Ph.D., EPO Campus Box 334, University of Colorado, Boulder, CO 80309.

Present address: Neurobiology Unit, Scripps Institution of Oceanography, University of California, San Diego, La Jolla, California 92093.

Copyright (c) 1988 Society for Neuroscience $0270-6474 / 88 / 082758-11 \$ 02.00 / 0$
}

numerous experiments have shown that RS fiber stimulation produces coordinated behavior patterns (for review, see McClellan, 1986). In addition, anatomical and neurophysiological studies reveal that the cells have both the inputs and outputs for integrative motor control. The medial RS neurons, for instance, and the ventral parts of the nucleus reticularis gigantocellularis, receive di- or polysynaptic input from the vestibular system, tectum (Peterson et al., 1974, 1975; Peterson and Fukushima, 1982), and higher integrative centers such as the cortex (Peterson, 1984). RS axons serve the entire length of the spinal cord with widespread terminations (Peterson et al., 1975; Martin et al., 1979a, b, 1981). These large, fast-conducting RS neurons make mono- and polysynaptic excitatory connections to both limb and axial motoneurons (Peterson et al., 1979). In short, a wide range of investigations implicate the RS system in controlling coordinated sequences of body movements (Kuypers, 1982; Peterson, 1984).

What are the roles of individual RS neurons in the control of these complex motor activities? This is difficult to discern because of the dispersed anatomical organization of the RS system. However, in lower vertebrates, particularly lamprey and teleost fishes, the RS system consists of a number of identified cell types, serially reiterated along the length of the medulla (Rovainen, 1967; Kimmel, 1982a). In zebrafish larva, for example, 27 RS neuronal types have been identified. Of these, 19 are bilateral pairs that are individually identifiable (Metcalfe et al., 1986). It is possible to analyze such cells individually in much the same way as identified neurons in invertebrates (Stein, 1978).

The Mauthner (M-) cclls of teleost fishes are the most well studied of these RS neurons, especially with regard to numerous seminal studies of their synaptic physiology (Faber and Korn, 1978, 1987; Korn and Mallet, 1984) and development (Kimmel, 1982b). This paper concerns the functional role of this pair of cells, which reside on either side of the midline at the level of the eighth cranial nerve. M-cells are involved in a high-speed escape maneuver known as the C-start, which lasts about 70$100 \mathrm{msec}$ (for review, see Eaton and Hackett, 1984). In the first phase of the C-start (stage 1), the body of the fish assumes a C-like profile. In stage 2 , the fish accelerates in an escape trajectory away from the stimulus (Blaxter et al., 1981; Eaton et al., 1981). The complexity of this motor pattern is reflected by profound changes in a wide field of neurons whose activity accompanies the C-start (Eaton and Hackett, 1984; DiDomenico and Eaton, 1988; Nissanov and Eaton, 1989). Both spinal and supraspinal motor pools are recruited so that much of the animal's motor system is subsumed. This includes not only the trunk musculature but also the musculature controlling the eyes, jaw, operculum, and fins (Diamond, 1971; Eaton et al., 1977; Hackett and Faber, 1983b). Because of their functional 
and anatomical similarities to the medial RS neurons found in higher vertebrates, the M-cells are an excellent model for studying mechanisms of movement control.

Numerous studies implicate the M-cell in the C-start (Eaton and DiDomenico, 1985; Eaton et al., 1986). One M-cell invariably fires a single spike $8 \mathrm{msec}$ before onset of the stage 1 movement (Eaton et al., 1981, 1982). In addition, it is known that the firing of the $\mathbf{M}$-cell initiates a large electromyogram (EMG) of the contralateral trunk musculature (Yasargil and Diamond, 1968; Diamond, 1971; Rock, 1980; Rock et al., 1981; Hackett and Faber, 1983a; Hackett and Greenfield, 1986). These findings provide a starting point for asking fundamental questions regarding the generation of the C-start: What is the contribution of the M-cell to the first stage of the C-start? How is escape trajectory controlled? And what processes underlie production of the second stage?

Recent work from various systems demonstrates the importance of detailed kinematic analysis for understanding the neural mechanisms underlying the expression of motor acts (Ayers et al., 1983; Smith, 1986). We utilize such a quantitative approach to gain insight into understanding the relationships between the output activity of the M-cell, other neural signals during the C-start, and the movement itself. We recently developed a highspeed digital imaging system that greatly facilitates the analysis of the C-start and its corresponding Mauthner and EMG recordings. Our findings clarify the functional role of the M-cell in the production of the C-start and provide new insights into the neural operations underlying this distinctive motor act.

\section{Materials and Methods}

Animals, testing arena, and the stimulus for triggering $C$-starts. Experiments were done on adult goldfish $(10-13 \mathrm{~cm}$ standard length; see Eaton et al., 1981, 1982), and motor responses of individual goldfish were studied in an aquarium $(40 \times 40 \mathrm{~cm}$ by $12.8 \mathrm{~cm}$ deep) with opaque walls and water temperature at $24^{\circ} \mathrm{C}$. Fish were restricted by means of clear plastic partitions to a central arena $(35.5 \times 35.5 \mathrm{~cm}$ by $12.8 \mathrm{~cm}$ deep).

Escape responses were elicited by small vertical displacements of the entire test aquarium (Fig. 1). In small flexible arenas such as ours, uniform stimulus fields are inherently difficult to produce. The presence of directional gradients can be assessed by mcasurcments of the sound pressure (upper trace, Fig. 1). Sound pressure was greatest at the bottom center of the arena and fell off by about $33 \%$ from the bottom to the surface and by $43 \%$ toward the middle of the sides, with the corners reduced by an average of $15 \%$. Fish are thought to be sensitive to a variety of aspects of such a stimulus (such as sound pressure, displacement or acceleration), but for present purposes we describe the stimulus as "displacement."

Digital imaging and behavioral testing. To quantify motor responses, we used a matrix camera, a high-speed digital imaging device based on a 10,000 bit photodiode array that gathers data in high-speed, shortduration bursts (333-500 frames/sec) for computer display and analysis (Fig. 2; Nissanov, 1987). Minimum intertrial interval was $2 \mathrm{~min}$. Response measures were calculated from smoothed midlines produced by analysis programs. Performance criteria (latency, start and end of the mechanical stages, directionality, etc.) were incorporated into the analysis software for automated calculation. Performance and response parameter definitions are included in the Results.

For behavioral trials, a fish was placed in the test arena and allowed to acclimate for $15 \mathrm{~min}$. The fish could not see the investigator. Displacement stimuli were delivered when the animal was stationary and positioned so it could turn without striking a wall. This was determined by an observer who watched the motions of the fish on a real-time matrix display on the screen of a digital oscilloscope. Mean stimulus interval was $233 \pm 14.5 \mathrm{sec}$ ( \pm SEM, $n=127$ ). Starting at a subthreshold level, stimuli were increased stepwise until a C-start was elicited. Stimulus strength was then decreased and again incrementally tested for 5 trials for each animal to determine the average response threshold.
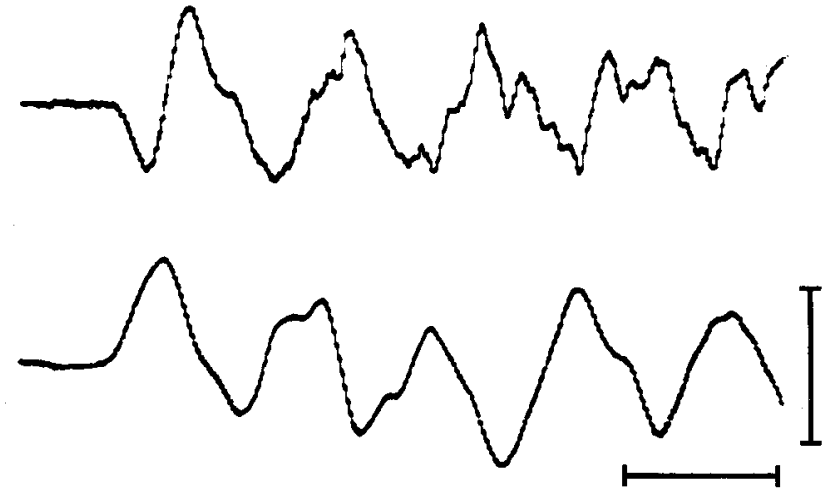

Figure 1. The stimulus waveform. The stimulus was made by switching 1.5 waves of the $60 \mathrm{~Hz}$ line voltage to a $120 \mathrm{~V} \mathrm{AC}$ solenoid, from which was suspended the test aquarium on a rigid steel frame. The amplitude of the movemicnt of the arena was controlled by varying the voltage to the solenoid. A zero-crossing detection circuit ensured reproducible waveform production. Upper trace shows sound pressure measured with a hydrophone. The displacement (lower trace) was measured with a photoelectric interrupter module (Brown, 1974) mounted on the steel frame of the aquarium holder. The output of the interrupter module was calibrated by direct visual observation in synchronized stroboscopic light under a compound microscope equipped with an optical micrometer. As shown here, resonance frequency of the arena was about $50 \mathrm{~Hz}$. Scale bars: upper trace, $87 \mathrm{~Pa}$; lower trace, $64 \mu \mathrm{m}$; horizontal, $20 \mathrm{msec}$.

Chronic single-cell recordings. For chronic recordings, the animal was deeply anesthetized (ethyl-m-aminobenzoate, 1:4000, Sigma), restrained, and continually perfused with water $(100 \mathrm{ml} / \mathrm{min})$ through the mouth to oxygenate the gills. To block nociception and retard bleeding, the perfusion water contained anesthetic $(1: 10,000)$ and was chilled to $10^{\circ}-12^{\circ} \mathrm{C}$

We used a quasi-stereotaxic method for positioning the microelectrode into the brain stem near the M-cell soma (Eaton et al., 1981). Distance from the electrode to $\mathrm{M}$-cell for the 5 preparations averaged $324 \mu \mathrm{m}$ on the first penetration. For precise positioning, we searched for the prominent action potential produced by the M-axon initial segment, the so-called "M-spike" (arrow, Fig. 4), as an electrical landmark (Furshpan and Furukawa, 1962). To activate the cell, we stimulated the axon antidromically as previously described (Eaton et al., 1981, 1982). M-spike thresholds (3.1-6.2 V) and latencies (0.62-0.76 msec) were as reported previously (e.g., Faber and Korn, 1978; Eaton et al., 1981).

Stainless steel electrodes with rounded tips of about $20 \mu \mathrm{m}$ diameter and impedances of $0.5-0.9 \mathrm{~m} \Omega($ at $1 \mathrm{kHz})$ were used for conventional single-ended recordings (bandwidth, $0.3-10 \mathrm{kHz}$ ), which were digitized by computer and displayed with an $X-Y$ plotter. Our electrodes are highly selective for the M-spike, which could be detected at distances of $400 \mu \mathrm{m}$ or more, whereas fields of smaller cells were lost after small changes in electrode position.

Following initial penetration, the recording electrode was repositioned until the M-spike was at least $0.5 \mathrm{mV}$, just outside the axon cap neuropil (Fig. 2 in Eaton et al., 1981). At this distance (75-100 $\mu \mathrm{m})$, the electrode was unlikely to damage the cell during the C-starts. The electrode was fixed in this location with a skull implant assembly (Zottoli, 1977; Eaton et al., 1981, 1982) and attached to a $75 \mu \mathrm{m}$ insulated recording lead connected to a rotating commutator.

Because recorded M-spike amplitude can decline during an experimental session due to electrode movement introduced by the high accelerations during the $\mathrm{C}$-start, at least 2 procedures were used to confirm that the recorded spike was from the M-cell rather than some other reticulospinal neuron that participates in the behavior. First, we compared 2 independent measures of M-spike amplitude versus distance from the cell to see if the chronically recorded $M$-spike amplitude at the end of the experiment fell on the expected voltage-distance curve for each individual cell-electrode combination determined at the beginning of each experiment when we initially located the cell. After chronic recording, we electrolytically deposited iron at the electrode tip position by passing current from the electrode and histochemically staining the spot (Prussian blue procedure; Eaton et al., 1981). The distance 


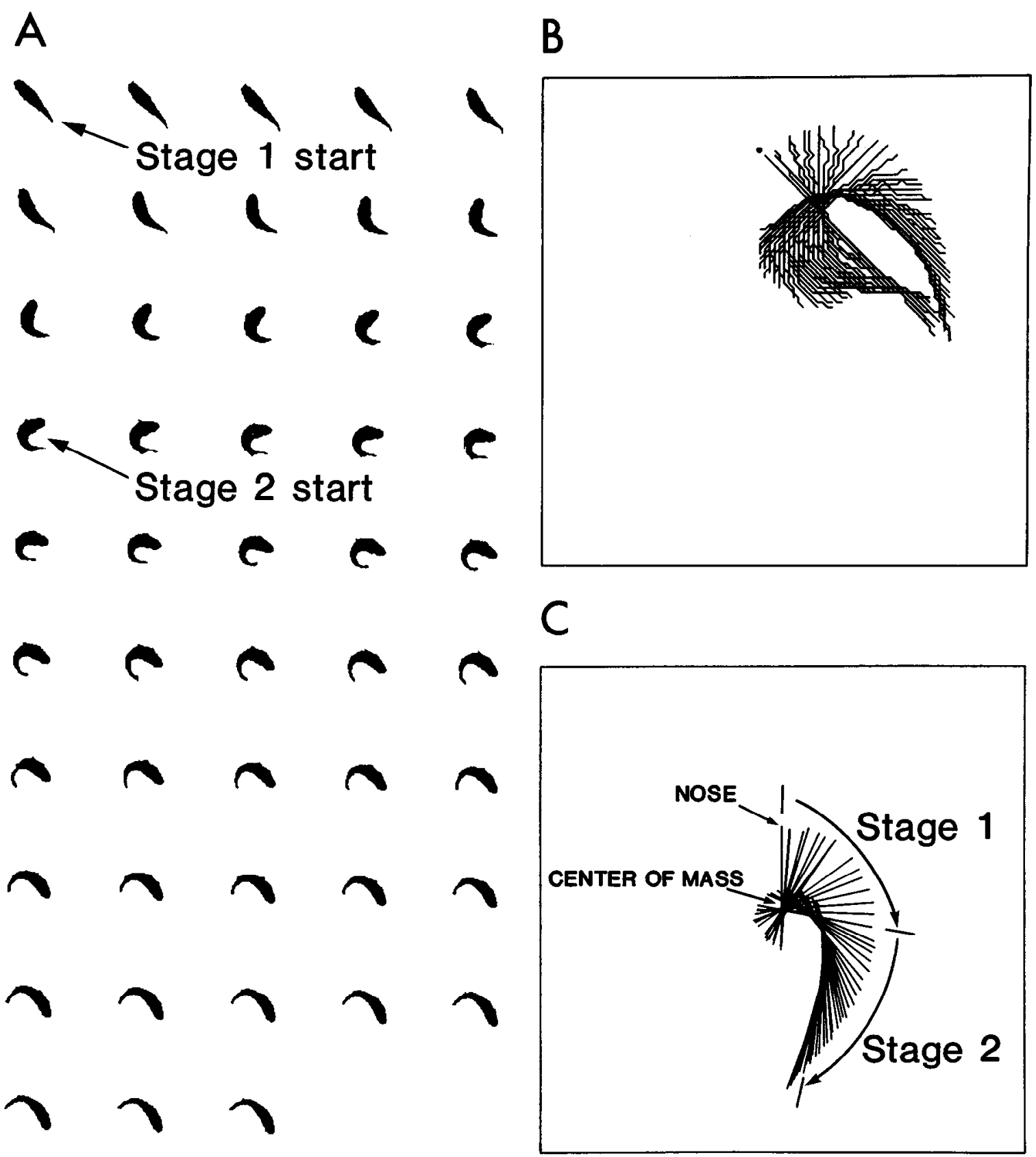

Figure 2. Digital display and computational steps for movement analysis. $A$, Digitization of a complete response at 2 msec intervals (read leftright, top-bottom). Each subsequent image has been moved a fixed distance to the right. In $B$, the original images were reduced by a series of algorithms to a set of coordinates representing the midline of the fish. To do this, the first steps determined the outer edge of pixels forming the border of the fish against the background. This outline was thinned, the midline was calculated, and the computer determined which end was the head. The $X-Y$ coordinates of the resulting line were reconstructed as shown in $B$. The nose of the fish is indicated by the dot at the first midline, where the body is shown in its full stretched position at the start. Subsequent midlines are superimposed so that the image is as viewed from above. The irregularity in the lines is due to positional error introduced by pixels near their thresholds because they were on the border of the fish against the background. This caused an equivalent error in the midline calculation. To reduce this for final treatment of the data, we calculated a linear regression on the points comprising the first $40 \%$ of the body length $(C)$. For standard display purposes the resulting set of midlines was rotated and repositioned so that the nose pointed upward on the figure and the center of mass was positioned at the middle. As previously determined from actual measurement, the center of mass is on the midline, at a distance of $33 \%$ from the nose to caudal peduncle (Webb, 1978 ; Nissanov, 1987). Our crilerion to determine the end of stage 1 and the onset of stage 2 was when the center of mass of the body of the fish became displaced by more than $0.75 \mathrm{~cm}$ from its position at the start. In the example shown, this division between the 2 stages occurs at frame 16,30 msec after the start.

from the center of the stained spot to the M-cell initial segment was measured and compared with the corresponding distance-voltage curves at time of implantation. The M-spike amplitudes $(0.20-0.58 \mathrm{mV})$ for the 5 animals, and the corresponding distances $(80-240 \mu \mathrm{m})$ differed from their respective voltage-distance curves by a mean of $+0.08 \mathrm{mV}$. This translates to a recording distance of only $21 \mu \mathrm{m}$ closer to the M-cell than expected, an agreement within the uncertainty in knowing the center of the histochemical marker and otherwise anticipated because the voltage-distance curves were determined with the animal chilled and anesthetized.

For the second verification procedure we rechecked the antidromic $\mathrm{M}$-spike latency and threshold at the end of behavioral testing in 3 
preparations before passing current from the recording electrode. The latencies $(0.61-0.81 \mathrm{msec})$ were close to those observed at the time of the implant $(0.62-0.76 \mathrm{msec})$. The effect of the current-passing procedure on the M-spike was as previously described (Eaton et al., 1981): The spike was greatly reduced in amplitude or reversed in polarity because the current caused a lesion close enough to the cell to block localized spike generation.

$E M G$ recordings. EMG electrodes consisted of pairs of insulated 75 $\mu \mathrm{m}$ copper wires inserted into the dorsal white epaxial musculature in the midtrunk region. The tips of the 2 wires of a pair were separated by about $5 \mathrm{~mm}$ and inserted to a depth of $3-4 \mathrm{~mm}$ (Basmajian and DeLuca, 1985). Recording leads were anchored to a 3-0 self-threading screw inserted at the caudal edge of the skull. EMG signals were differentially amplified $(0.3-10 \mathrm{kHz})$, digitized, and displayed with an $X-Y$ plotter. Integrals of the EMGs were computed from the digitized records at $50 \mu \mathrm{sec}$ sampling rates.

\section{Results}

Form of C-starts to displacement

The displacement stimulus, which may emulate the waveform of a predatory strike (Weihs, 1980; Nissanov and Eaton, 1989), was found to be a particularly effective stimulus for C-starts in goldfish. It was difficult to habituate the animals to the stimulus: As described below, response probability was high even with short interstimulus intervals; thresholds for 154 responses were in the range of 3-6 $\mu \mathrm{m}$ (mean $=4.3 \pm 0.10 \mu \mathrm{m}$ ) and response movement latencies had a mean value of $13.5 \pm 0.30 \mathrm{msec}(n$ $=168$ ) as measured from stimulus onset to the frame preceding observable movement.

By examining the coordinates of the center of mass as the animal executed the motor response, the 2 mechanical phases of the C-start were readily identified from the digitized images. Figure 2 gives an example of one response $(A)$ and two of the steps ( $B$ and $C$ ) in the analysis. During the first phase of the response, stage 1 , there is a rotational movement about the point representing the stretched body center of mass of the fish. The rotation is clearly visible in the midline analyses in Figure $2, B$ and $C$, as the central intersection of the line segments. Stage 2 is characterized by an axial acceleration of the center of mass that accompanies forward propulsion. During stage 2 the animal may also continue to turn. The escape trajectory is defined by sum of the rotations of the 2 stages plus the accompanying axial movement.

Responses to displacement appear similar to the C-starts previously described for various other types of stimuli; visual, auditory, vibrational, and multimodal as caused by objects dropped into the water or actual predatory strikes (Webb, 1982, 1986; Lauder, 1983; Eaton and Hackett, 1984). For purposes of comparison, we show in Figure $3 A$ a range of C-starts of goldfish escaping from a ball dropped into the water directly over the fish as described by Eaton et al. (1977, 1981, 1982). The figure shows that within $70 \mathrm{msec}$ of the beginning of the response to the ball drop, goldfish can execute trajectories oriented anywhere in the horizontal plane, from straight ahead if the stimulus is behind the fish (Fig. 3A1) to turns of $180^{\circ}$ if the stimulus is in front (Fig. $3 A 6$ ). In response to the displacement stimulus, the fish gave C-starts representing the full complement of possible positions and trajectory angles seen to the ball drop stimulus (Fig. $3 B$ ). The left-hand frames of Figure $3 B(1-6)$ show the stage 1 midlines and the corresponding right-hand frames (16) give the entire response from start to $70 \mathrm{msec}$.

In the summary diagram of Figure 4 , the range of responses is mapped according to the position of the center of mass after $70 \mathrm{msec}$. The data include responses of 38 animals responding to displacement. The heavy vertical arrow is a scaled representation of a $10-\mathrm{cm}$ goldfish in the start position at the time of the stimulus. The nose points toward a heading of $0^{\circ}$. At the origin of the polar plot is the position of the center of mass at the start. Distance from the origin is the distance moved by the center of mass $70 \mathrm{msec}$ after the start frame; the angular coordinate shows six $30^{\circ}$ sectors into which the fish moved by 70 msec relative to the start. The accompanying percentages give the proportion of responses observed in the various sectors. For example, for sector II responses $\left(15^{\circ}-45^{\circ}\right)$, the mean distance traveled was $4 \mathrm{~cm}$, and sector II responses constituted $11 \%$ of the total. In sum, $98 \%$ of the responses were with the center of mass in the sectors ranging from $15^{\circ}$ to $135^{\circ}$ from the start position.

\section{Performance of $C$-starts}

A quantitative performance analysis of stages 1 and 2 is given in Figure 5, which illustrates wide ranges in performance flexibility, as indicated by all measured parameters. First, it is seen that the duration of the majority of stage 1 turns lasted from 15 to $40 \mathrm{msec}$ (Fig. 5A), and the range of observed angles extended over $70^{\circ}$ (Fig. $5 B$ ). During stage 1 , the animals turned on the average nearly $60^{\circ}$ from the start position (Fig. $5 B$ ). The important point from these data is that stage 1 cannot be considered an event of fixed performance but, in fact, is quite variable in terms both of its duration and angle.

Stage 2 angle was defined as the angle achieved during a 50 msec interval after the end of stage 1 . The majority of these total angles fell within a $120^{\circ}$ range; that is, if the stage 1 turn is given a positive value, the stage 2 turn could continue in the same direction or the animal could reverse its initial turn to produce a negative stage 2 angle. In either case, the maximum angle achieved for any stage 2 was about $100^{\circ}$, though taken together the mean of all the stage 2 angles was close to zero $\left(-4.2^{\circ}\right)$ relative to the angle at the end of stage 1 (Fig. $5 \mathrm{C}$ ).

The range of trajectories probably stems from differences in the neural command caused by external factors such as the stimulus gradients in the test arena (see Materials and Methods). Fish direct their responses away from the source of aversive sound stimuli (Blaxter et al., 1981). Because we did not attempt to control for the fish's exact orientation in the test arena, the trajectory angles are probably the randomized result of differences in stimulus direction perceived by the fish.

Besides the variability in trajectory angle, there was also a variability in response strength. During most responses, the center of mass of the fish moved a distance of $2-6 \mathrm{~cm}$ (mean $=$ $4.1)$ in $70 \mathrm{msec}$ from the coordinates of the starting location (Fig. 5D). Did the nonuniform stimulus field in the test arena also affect the variability in distance moved? To test this, we performed a control experiment by comparing the magnitude of 2 groups of responses at 2 different stimulus intensities: 14 responses at an intensity of $8.6 \mu \mathrm{m}$ and 34 responses at 12.2 $\mu \mathrm{m}(0.62 \mathrm{log}$ increase). This difference in intensity is a reasonable control because it was greater than the measured gradients in sound pressure in the arena (see Materials and Methods). The mean distance traveled at the $8.6 \mu \mathrm{m}$ intensity was $3.7 \mathrm{~cm}$ $( \pm 0.31)$ compared with $4.1 \mathrm{~cm}( \pm 0.22)$ at the $12.2 \mu \mathrm{m}$ intensity, a statistically insignificant difference ( $t$ test, $p>0.1$ ). We conclude that there is no large effect of stimulus intensity on response performance to displacement under the conditions of our experiments. These findings suggest that performance is maximized during the C-start to displacement. 
A
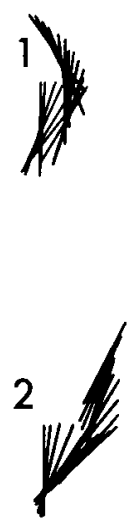

5

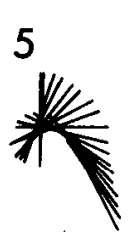

6

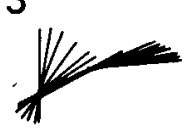

4

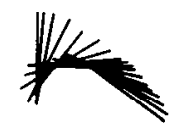

2
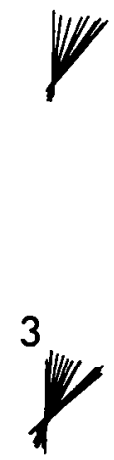
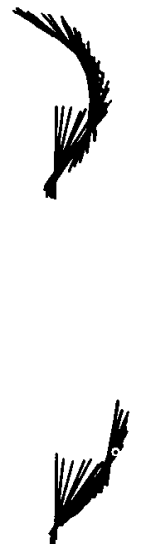

5

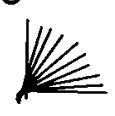

6
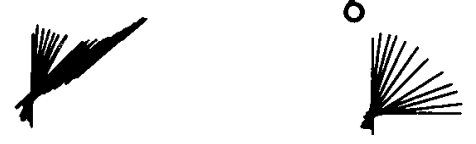

4
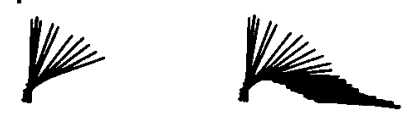

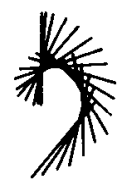

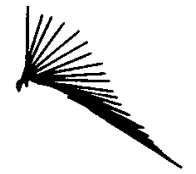

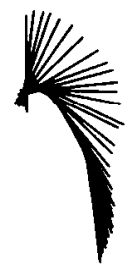

Figure 3. Comparison of C-starts in response to a ball dropped into the test arena $(A)$ and the displacement stimulus $(B)$. Responses in $A$ were elicited by a $4.25-\mathrm{cm}$-diameter plastic ball electronically released $15 \mathrm{~cm}$ above the water directly over the fish. The 6 images $A$ were digitized from cine records taken at 500 frames/sec and analyzed according to the new methods devised for the matrix camera system. Midlines are at 4 msec intervals and include both stage 1 and 2. Images in $B$ are examples of responses to displacement and show the stage 1 midlines (on the left of each pair) as well as the complete response (stage 1 plus stage 2) on the right of each pair. Midlines are at 2 msec intervals.

A second interpretation of the variation in distance moved was that the variability was due to differences in the intervals of stimulus presentation because of the fact that we waited various lengths of time for the fish to become centralized in the arena before delivering a stimulus. Conceivably, the fish gave smaller responses at shorter intervals. However, we found that performance did not vary systematically with repetition rate. The data in Figure $5 D$ were obtained at an average interstimulus interval of $233 \mathrm{sec}$ and the mean distance traveled was $4.1 \mathrm{~cm}$. In comparison, at a fixed interstimulus interval of $120 \mathrm{sec}$, the mean distance traveled was the same, $4.1( \pm 0.15) \mathrm{cm}(n=84)$. This was determined from a separate group of 16 control animals that received 10 stimuli each. The fish were affected in some ways by interstimulus interval because response probability in the control group was observed to fall from a mean value of $98 \%$ over the first 3 trials to $80 \%$ over the last 3 . However, despite this difference in probability, there was still no significant effect on performance: average center of mass movement for trials (in which the animal gave a response) was $4.0( \pm 0.22) \mathrm{cm}$ for the first 3 trials versus $4.2( \pm 0.37) \mathrm{cm}$ for the last 3 ( $p>0.50, t$ test). Thus, over the tested repetition rate (which was maximum for our instrument system), response strength did not vary even in cases when response probability declined.

\section{Relationship of stage 1 to stage 2 and escape trajectory}

In prey-predator interactions, a crucial determinant of the outcome is the escape angle the prey fish achieves at a given point in time relative to the start of its escape sequence (Howland, 1974; Weihs and Webb, 1984). Since directionality is inherent in the stimulus signal, the neural commands for escape trajectory could possibly be determined during the initiation of the C-start. From casual inspection of data of the type in Figure 3 , it seemed that this might be the case. For starts in which the animal moved ahead into sector $I$ ( $\pm 15^{\circ}$ from the starting orientation), the stage 1 turn was small, whereas in those C-starts with large trajectory angles (sector V), there was a large stage 1 turn as well. These observations were born out for a large number of trials in the linear-regression analysis illustrated in Figure 6. These findings show that the turning angles of stages 1 and 2 are not independent and suggest that the neural commands for escape trajectory are organized very early, at least by the end of stage 1 .

\section{$M$-cell recordings in freely swimming animals}

The C-starts in the present study appear identical to those seen in goldfish when the M-cell is known to fire. IIowever, it was not a forgone conclusion that the M-cell is involved in the 


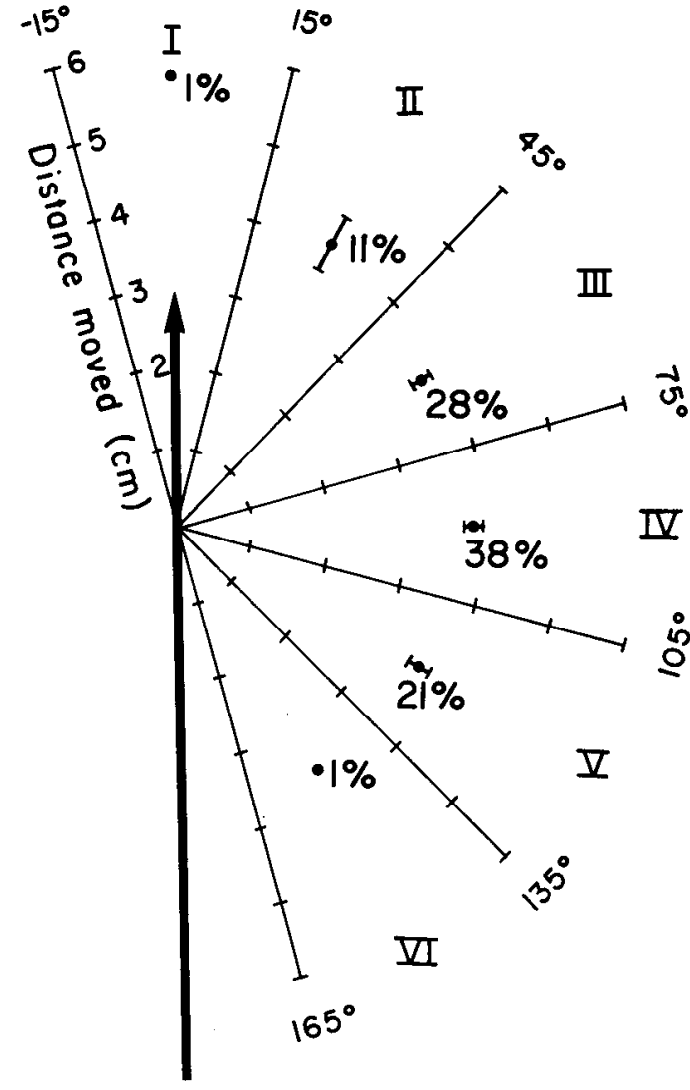

Figure 4. Sector analysis of the position of the center of mass of 148 $\mathrm{C}$-starts at $70 \mathrm{msec}$ after the beginning of the response. The data from individual trials were first written as a polar scatter plot (not shown) divided into 12 sectors of $30^{\circ}$ each. For statistical purposes all values initiated to the left were reflected onto the right side of the graph. The distances of all the center of mass positions falling into each sector were averaged and plotted as the points on the graph along with the percentages of responses in each sector. These points are similar, but not identical to, the escape trajectories because the animals' headings at 70 msec can vary in the different sectors.

responses to displacement. It is known that the $\mathrm{M}$-cell is not required for escape responses in goldfish (Eaton et al., 1982). Thus, we next wanted to know if firing of the M-cell accompanied C-starts elicited by displacement. To do this, we recorded from one of the M-cells in each of 5 animals freely swimming in the test arena. Altogether, 36 responses to displacement were recorded. In 18 trials the stage 1 contraction was on the side opposite the recorded M-cell soma. All these responses were accompanied by an initial firing of the M-cell. This laterality was expected, as the $\mathrm{M}$-axon descends into the spinal cord on the side of the body opposite the $\mathrm{M}$-cell soma and activates contralateral motoneurons. An example of one of the M-cell recordings with the corresponding motor response is shown in Figure 7. The mean latency from stimulus onset to the M-spike was $3.4 \pm 0.3 \mathrm{msec}(n=17)$. As in previous records of this type, the M-spike is followed at a mean interval of $1.9 \pm 0.07$ msec $(n=18)$ by a second negative deflection, which is probably a volume-conducted representation of the first large EMG from the body musculature during stage 1 (Eaton et al., 1981). In the present study, the first movement of stage 1 began after a mean of $8.0 \pm 0.3 \mathrm{msec}(n=17)$ following the M-spike. The observed values ranged from 6.3 to $10.7 \mathrm{msec}$, îhe same range $(6-10 \mathrm{msec})$ observed previously from data obtained from film (Eaton et al.,
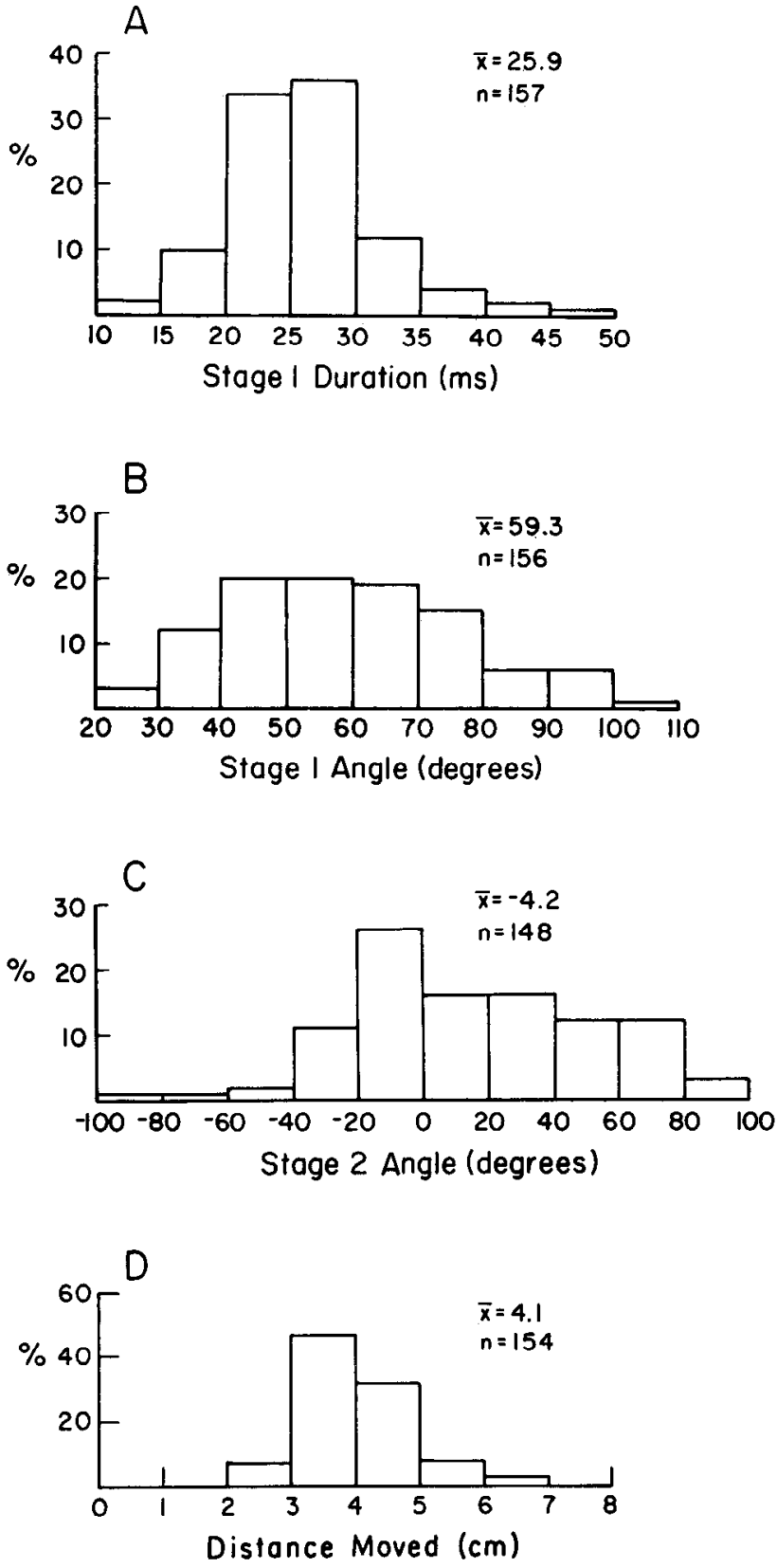

Figure 5. Frequency histograms of various performance characteristics of the C-starts of 38 fish. These data show, collectively, that the component parts of the $\mathrm{C}$-start are not fixed entities but vary over considerable ranges when measured in terms of duration of stage $1(A)$, stage 1 turning angle $(B)$, stage 2 angle $(C)$, and distance moved $(D) 70 \mathrm{msec}$ after the beginning of the response.

1981). These findings demonstrate the tightly locked temporal correspondence between $\mathrm{M}$-cell firing and the onset of the C-start.

Probability of firing of the M-cell followed the expected pattern seen in previous work. Of the 18 responses with the initial contraction on the side opposite the recorded M-cell soma, all 18 were preceded by an M-spike. Of the 16 responses with the initial contraction on the same side as the recorded M-cell soma, 15 had no preceding M-spike and one did. No M-spikes were recorded in 2 trials in which there was no response. Chi-square analysis showed that this distribution was significantly different from random $(p<0.005)$. 


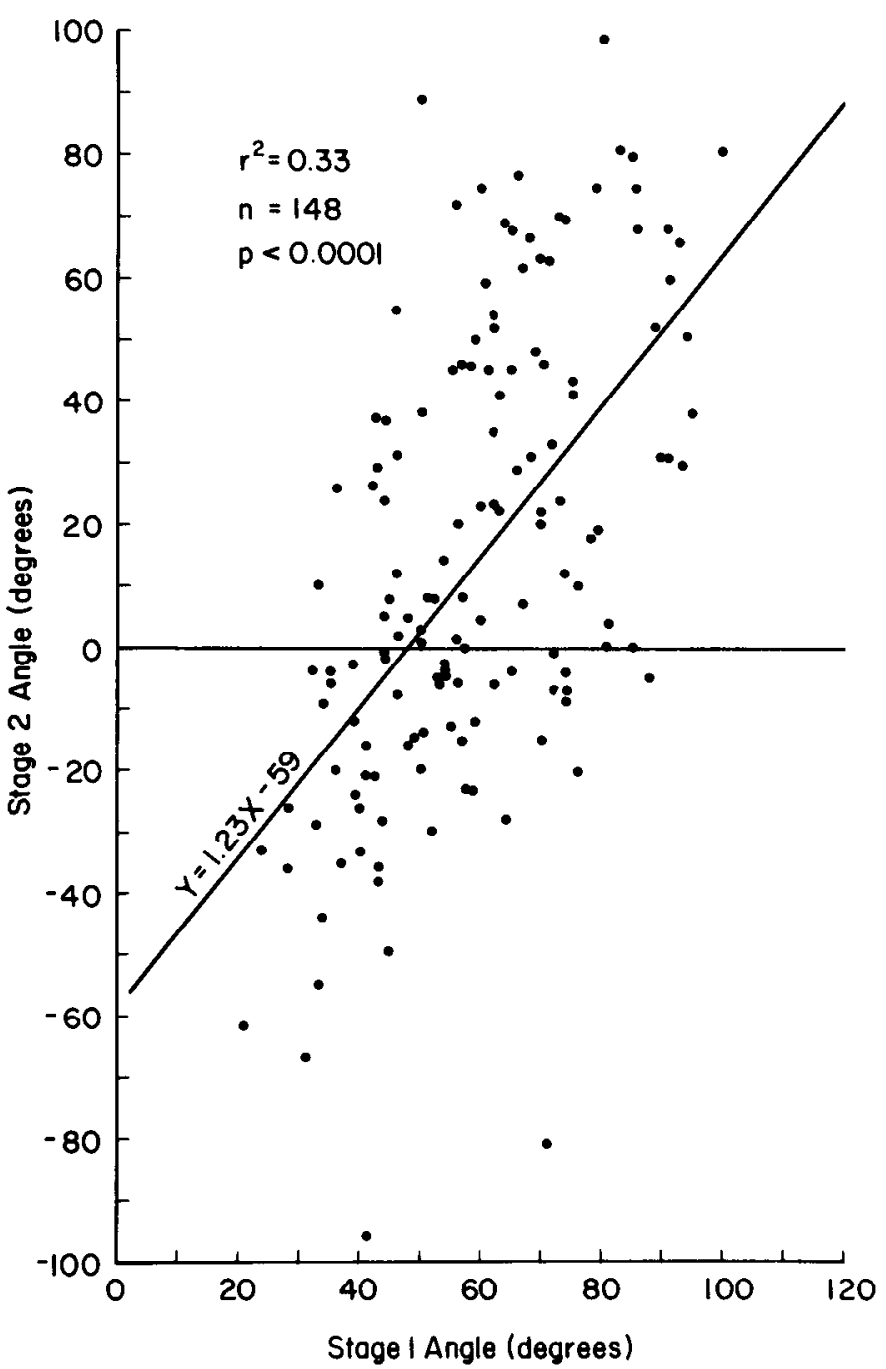

Figure 6. The correlation between stage 1 (abscissa) and stage 2 angles (ordinate). Linear regression showed that the correlation coefficient for the 2 measures was statistically significant (assumptions of normality and homoscedasticity were met).

The presence of one "wrong" response (when the M-cell was observed to fire and the animal turned toward the same side) indicates that even though the relationship between the M-cell firing and the response is strong, it is not perfect. A similar example was reported by Zottoli (1977). The exceptional response might have been initiated by the opposite (unrecorded) M-cell or by a "non-Mauthner" circuit that also can trigger escape in goldfish (Eaton et al., 1982). The M-spike in this case appeared to occur at the same time as the trunk EMG, which would make it about $8 \mathrm{msec}$ after the initiating $M$-cell fired. This is within the period in which the output of the delayed cell is expected to be completely blocked by the known crossedspinal inhibitory network (Diamond, 1971). In accordance with this, the animal was still able to execute a C-start.

\section{$E M G$ recordings and motor performance}

The above findings show that displacement elicits a rich variety of C-start trajectories. Next we inquired into the dynamic relationship between the neural commands and mechanical performance by examining the corresponding body EMGs of 5 animals during the motor response. The present results show
A

B
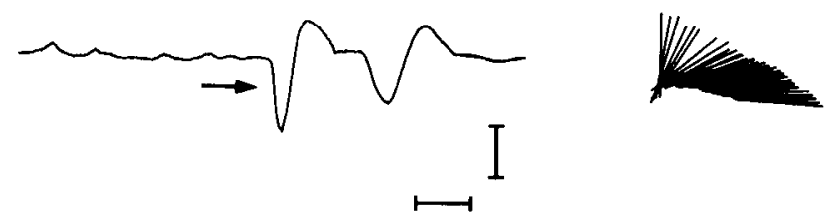

Figure 7. M-initiated C-start to displacement. $A$ is an example of an M-spike (arrow) recorded in a freely swimming goldfish. Positive polarity is upward on the figure. $B$ gives the midline display of the corresponding motor response ( $2 \mathrm{msec}$ intervals). The movement started $8.6 \mathrm{msec}$ after the $\mathrm{M}$-spike. Scale bars: vertical, $0.5 \mathrm{mV}$; horizontal, 1 msec.

that performance measures are closely associated with the duration of the body muscle EMGs that we recorded. We refer to the recording from the side of the initial large contraction as the "major" side and the recording on the opposite side as the "minor" side. Examples of 3 corresponding motor responses and major side EMG recordings are shown in Figure 8, where it can be seen that the records ranged considerably in duration, from a few large initial impulses to more prolonged bursts consisting of several large spikes: in 29 records of this type, 44\% had a single large spike, with the remainder $(56 \%)$ having from 2 to 5 , where "spike" was defined as any inflection at least $12.5 \%$ as large as the initial large one. In Figure 8 it is qualitatively evident that the duration of the major side EMG $(A l-C l)$ is roughly correlated with the magnitude of the stage 1 turn (A2$C 2$ ). This was analyzed quantitatively, as shown in Table 1 , in a linear-regression analysis of EMG durations and their rectified integrals versus stage 1 turn angles. The slopes of the resulting regressions were significantly different from zero. Thus, the quantified parameters of the body muscle EMGs that we recorded varied with the angle achieved during stage 1 .

The traces of Figure 9 give examples of both the major $(A)$ and minor $(B)$ side EMG recordings from the animal's trunk musculature during a fast-start response $(C)$. In Figure $9 . A$, the stage 1 EMG spike on the major side corresponds with a large initial spike on the minor side (Fig. 9B). This has been observed by others (Diamond, 1971; Zottoli, 1977) and may in part represent a volume-conducted reflection of the major side EMG (see below). However, the minor side EMG recordings also show a second set of inflections at the arrow (1), beginning at the onset of stage 1, approximately $22 \mathrm{msec}$ after the stimulus. These EMG inflections seemed to have little or no counterpart on the major side. As shown in Figure $9 B$, we estimated their beginnings as the first large deflection following the end of the initial major side burst. The majority ( $86 \%$ of 28 records) fell within a 5-15 msec range following the onset of the major side EMG (mean, $9.0 \pm 0.68$ ). This time of onset precedes the stage 2 onset (arrow, 2 in Fig. $9 B$ ) by a mean of $28.4 \pm 2.0 \mathrm{msec}(n=28)$.

Analysis of the relative sizes of the major and minor side EMGs shows that the second minor side EMG is not a volumeconducted representative of the major side. For example, in the signals shown in Figure 9, $A, B$, assume that the first minor side EMG pulse (in Fig. $9 B$ ) is a volume-conducted reflection of the large major side EMG (in Fig. 9A). The amplitude reduction is $25 \%$ of the major side (the full major side signal is not shown). The second minor side EMG (at arrow 1 in Fig. $9 B$ ) is 0.88 $\mathrm{mV}$, so we would expect to see its equivalent on the major side with an amplitude of at least 4 times larger, or $3.5 \mathrm{mV}$. However, 

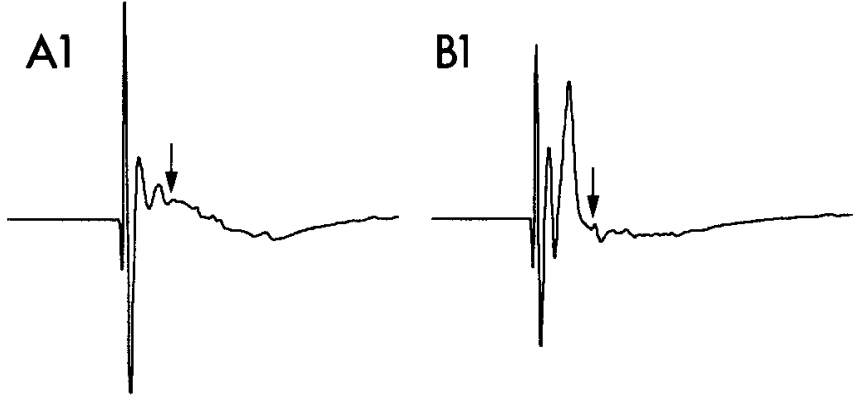

A2

B2

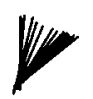

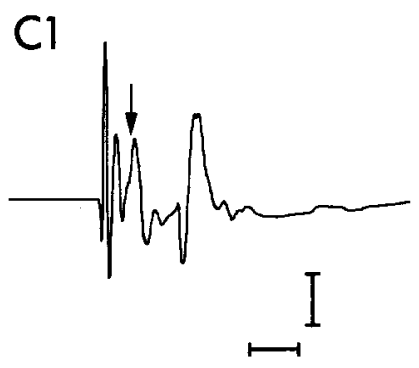

C2

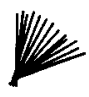

Figure 8. The relationship between the midtrunk EMG signal and the corresponding C-starts. Shown are 3 examples with the EMGs from the major side on top $(A 1, B 1$, and $C 1)$ and the stage 1 and complete midlines of the motor responses ( 2 msec intervals) below $(A 2, B 2$, and $C 2)$ all from the same animal. The start of each motor response is indicated by the arrows over the upper traces. Scale bars: vertical, 2 IIIV; horizontal, 5 msec. the corresponding major side EMG signal is at most only 0.38 $\mathrm{mV}$, nearly 10 times smaller. We conclude that the second, minor side EMG corresponds to a local event of the minor side midtrunk musculature.

\section{Discussion}

This study shows that stages 1 and 2 of the C-start grade into each other to produce a continuous and wide range of trajectory angles for escape. It is the combination of stage 1 and 2 angles and the onset time of stage 2 that determines the escape trajectory angle. This formulation of the C-start motor pattern leads to a new model of the underlying neural mechanism that is consistent with EMG recordings obtained during execution of the behavior. To develop this point we first contrast our current view of the motor pattern with the previous description.

In the present study, the range in trajectory angles corresponds to the previously observed variability in trajectories following a localized stimulus source, a ball dropped into the water near the fish (Fig. 3). Previously, this variability seemed to arise within stage 2 , as indicated by calculations of the coefficient of stereotypy (Barlow, 1968) measured according to the position and head speed of the rostrum of the fish (Eaton et al., 1981). As a matter of convention, stage 1 parameters were measured at a fixed point, $20 \mathrm{msec}$ after start of movement. We found that acceleration was relatively uniform and that the head moved in a consistent way during this time interval (Eaton et al., 1981). When considering these measurements, stage 1 was less variable (and therefore more stereotypic) than stage 2. In contrast, the present analysis is based on a completely different, biomechanical, approach that uses measurements relative to the center of mass (Webb, 1975). This shows that stage 1 can vary both in duration and angle achieved and suggests dynamic controlling mechanisms in operation from the earliest moments of the behavior.

Of the range of trajectories we observed, one extreme is represented by responses where the animal in stage 2 continues in the same direction as the initial stage $1 \mathrm{C}$-bend (Fig. 3, B5, 6). At the other extreme, the "fast forward displacements" (Eaton et al., 1977, 1981) are responses where stage 2 is a reversal of the initial stage $1 \mathrm{C}$-bend (Fig. 3, B1, 2). Although stage 2 may result in part from release of elastic forces caused by the stretch of the minor side during stage 1 (Johnsrude and Webb, 1985), purely mechanical effects cannot be the entire explanation for the stage 2 propulsion: in the case of the fast forward displacements, the high stage 1 acceleration (Webb, 1975, 1978) dictates that the second component needs to be as substantial in its consequences, and perhaps greater, than that which drives stage 1. Because of this, it is to be expected that a minimum of 2 body EMG signals are needed to produce C-starts: a first one to turn on those events leading to the stage 1 contraction of the major side and a second EMG to produce the propulsive stroke of the minor side during stage 2 .

EMG recordings from free-swimming animals reveal that there are, in fact, 2 signals: the previously observed one on the side of the major contraction (Fig. 8) and a second one on the minor side (Fig. 9B). The signal we recorded on the minor side seems to originate there, and no other distinctive EMG signals are seen in addition to it. For these reasons we conclude that the minor side EMG is the signal to the musculature to produce stage 2.

The major and minor side EMGs occur in a temporal se-

Table 1. Linear-regression analysis of the major side EMG duration or integral versus stage 1 angle

\begin{tabular}{lcclllll} 
Parameter & $\bar{X}$ & SEM & $n$ & $m$ & $b$ & $r$ & $p$ \\
\hline EMG duration (msec) & 10.6 & 1.15 & 26 & 1.2 & 30.7 & 0.43 & $<0.015$ \\
Stage 1 angle (deg) & 43.7 & 3.09 & 28 & - & - & - & - \\
Rectified EMG integral (mV-msec) & 32,932 & 2376 & 28 & $6.8 \times 10^{-4}$ & 21.5 & 0.52 & $\leq 0.005$
\end{tabular}



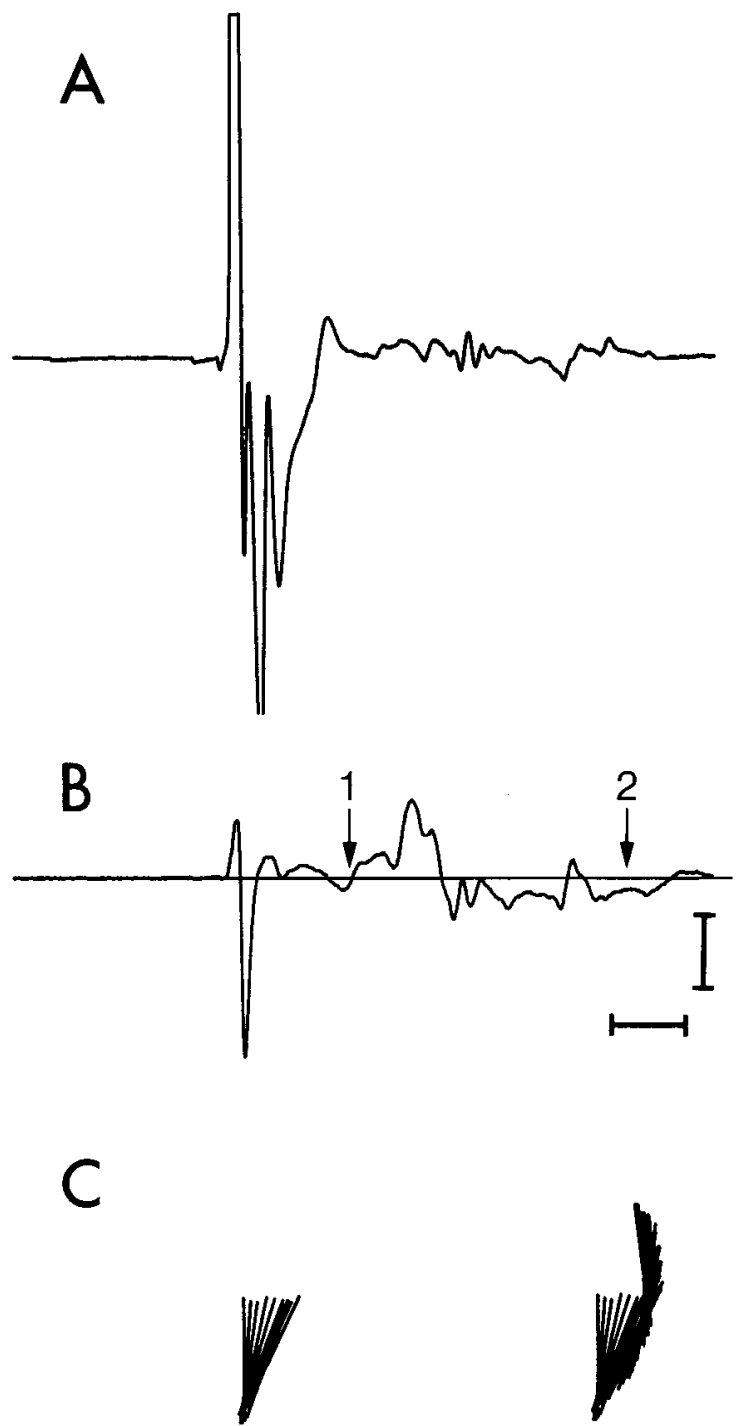

Figure 9. Comparison of major $(A)$ and minor side $(B)$ midtrunk EMGs during a C-start (C). The minor side EMG in $B$ consists of at least 2 components, the first of which secms to correspond to the major side EMG in $A$ and the second of which (starting approximately at the arrow l) is local to the minor side (see text). In this case, the onset of the second minor-side EMG burst occurs about the time of stage 1 onset (arrow I). Stage 2 begins at the second arrow (2). $C$ gives midlines for both stage 1 (left) and the complete response (right). Scale bars: vertical, $0.5 \mathrm{mV}$; horizontal, $5 \mathrm{msec}$.

quence and the first, on the major side, never occurs alone. In correspondence with this, we have not observed stage 1 to occur by itself in absence of stage 2 in the free-swimming goldfish. Because of their co-occurrence, the major and minor side EMGs are together the minimal signal for the command corresponding to the smallest behavioral unit, or "kernel," to use the words of Berkinblit et al. (1986). What is the basis of our current understanding of how the components of this behavioral unit are triggered and mediated?

Stage 1

Both the neuroanatomy and the physiology of the M-cell system suggest that this neuron can play a major rolc in triggcring and mediating stage 1 of the C-start. Typical of medial RS neurons, there is an extensive convergence of inputs onto the M-cell (Chang et al., 1987; Zottoli et al., 1987), and its output includes mono- and disynaptic connections to motoneurons (Auerbach and Bennett, 1969; Diamond, 1971; Hackett and Faber, 1983b; Fetcho and Faber, 1988). In 6 studies, stimulation of the M-cell has been observed to produce an all-or-nothing EMG of the body musculature (Yasargil and Diamond, 1968; Diamond, 1971; Rock, 1980; Rock et al., 1981; Hackett and Faber, 1983a; Hackett and Greenfield, 1986).

The M-cell output, and its accompanying fin, operculum, and eye muscle contractions, is known as the "M-reflex." Intracellular activation of the M-cell triggers the M-reflex and intracellular hyperpolarization of the M-cell completely prevents it (Rock et al., 1981; Hackett and Faber, 1983a). Thus, the case has been made that the $\mathrm{M}$-cell is both required for, and adequate to produce, a distinctive constellation of motor events including a major stereotypic contraction of the body musculature (Rock et al., 1981; Eaton and Hackett, 1984). In addition, it has been shown that the M-reflex has about the same $2 \mathrm{msec}$ latency as the onset of the stage 1 EMG following the M-spike (Diamond, 1971; Zottoli, 1977; Eaton et al., 1981; Hackett and Faber, 1983a; Hackett and Greenfield, 1986). Based on such findings, it has been suggested that the M-reflex is the stage 1 contraction (Rock et al., 1981; Hackett and Faber, 1983a; Hackett and Greenfield, 1986). We refer to this model as the "M-reflex hypothesis.

A central feature of the M-reflex hypothesis is the consistency of the body EMG that accompanies M-cell stimulation. It has been reported that additional EMG components do not show up even with eighth cranial nerve electrical stimuli that are suprathreshold for the M-cell, and even with interstimulus intervals as long as $10 \mathrm{~min}$ (Hackett and Greenfield, 1986). If stage 1 is considered to be a fixed event, the M-reflex hypothesis would predict that escape trajectory of the C-start is controlled by factors besides the stage 1 body contraction. These controlling factors would be possibly the fins, stage 2 contractions, or some combination. In contrast, our current findings show that in addition to stage 2 , the stage 1 contraction is a primary determinant of escape trajectory.

With the large number of trials in the present study, it is clear that stage 1 is not a fixed event. Stage 1 ranges from 10 to 50 msec in duration and from $30^{\circ}$ to $110^{\circ}$ in extent (Fig. 5, $A, B$ ). Furthermore, during these turns, stage 1 EMGs incorporate not only a single large EMG pulse, such as seen during the M-reflex, but also a number of other spikelike components (Fig. 8). The size of these EMGs varies parametrically with turn angle achieved during stage 1 (Table 1). Responses with single EMG pulses corresponded to only one class of the smallest turns. These new facts argue that stage 1 must be mediated by pathways that activate motoneurons in parallel to the M-circuit.

The findings of Rock et al. (1981) can be amended to this conclusion. These investigators used videotape recordings to compare the movement accompanying the M-reflex of a restrained bullfrog tadpole to the C-start in a freely-swimming animal. The M-reflex produced a tail movement of no more than $15^{\circ}$ in $60 \mathrm{msec}$ after the M-spike, whereas during the C-start the tadpole turned its body more than $120^{\circ}$ in the same interval (our calculations from their Figs. 1 and 3). Although Rock et al. (1981) suggested that this 8-fold difference might be due to a deteriorated preparation, their findings are consistent with our conclusion that the M-cell and its followers produce only a component of the normal stage 1 contraction. 


\section{Stage 2}

We present evidence that stage 2 is ballistically programmed and not dependent on movement-induced feedback. There is an interrelationship between the major and minor side contractions, such that large stage 1 angles are followed by large stage 2 angles (Fig. 6). From these kinematic considerations, it can be argued that for the animal to achieve a certain escape trajectory, it must anticipate the beginning of the stage 2 contraction. To do this, it needs to produce its directional command before stage 2 begins, at least $6-8 \mathrm{msec}$ prior to stage 2 onset. This interval is a minimum based on the $8 \mathrm{msec}$ latency from the major side EMG to the onset of stage 1 (which can be assumed to be very fast). In concert with these constraints, the minor side EMG does occur before the movement has been executed (Fig. 9). Because of this, it is most likely to be an internally generated signal expressing the output of the command system for the motor pattern.

In goldfish, no minor side EMGs have been observed following intracellular stimulation of the M-cell (Hackett and Greenfield, 1986). This suggests that stage 2 is activated by inputs independent of the M-cell. In contrast, however, Rock (1980) observed the minor side EMGs following stimulation of the M-reflex in the bullfrog, and Lee's (1982) ventral root recordings in Xenopus (his Fig. 3) also show a minor side component following intracellular M-cell activation. Thus, the central origin of the minor side signal and how it is triggered are not yet clear.

\section{Consequences of response flexibility}

We have shown that the C-start, and its underlying EMGs, form a movement pattern with a highly flexible range of outcomes. Relative to the start position, the responses were distributed across a continuous and wide range of angles representative of the variety of escape trajectories when the animal responds to known directional stimuli. Thus, the characterization and definition of this motor act consists of a continuous range of performance parameters. Because of its direct electrotonic connections from the acoustic system, and because of its high conduction velocity, the M-cell is probably the first RS neuron to fire during the C-start. As a result of its action, a major contraction of the body begins that directs the stage 1 contraction away from the side of the stimulus. In this context, the M-cell may be thought of as controlling the initial left-right decision of the escape sequence. However, additional parallel circuits are active in the presence of sensory stimuli. These contributing components are variable in their expression and result in a stage 1 that is longer in duration than the movement accompanying the M-reflex. In controlling the critical details of response angle, these cells must govern the extent of the initial turn by activating the body musculature in correspondence to the stimulus direction. Furthermore, circuits mediating stage 2 contribute to the trajectory angle by controlling both the onset time of stage 2 and the extent of its contraction.

\section{References}

Auerbach, A. A., and M. V. L. Bennett (1969) A rectifying electrotonic synapse in the central nervous system of a vertebrate. J. Gen. Physiol. 53: 211-237.

Ayers, J., G. A. Carpenter, S. Currie, and J. King (1983) Which behavior does the lamprey central motor program mediate? Science 221: 1312-1314.

Barlow, G. (1968) Modal action patterns. In How Animals Communicate, T. A. Seboek, ed., pp. 98-134, Indiana University Press, Bloomington.
Basmajian, J. V., and C. J. De Luca (1985) Muscles Alive, Williams \& Wilkins, Baltimore.

Berkinblit, M. B., A. G. Feldman, and O. I. Fukson (1986) Adaptability of innate motor patterns and motor control mechanisms. Behav. Brain Sci. 9: 585-638.

Blaxter, J. H. S., J. A. B. Gray, and E. J. Denton (1981) Sound and startle responses in herring shoals. J. Marine Biol. Assoc. U. K. 61: 871-879.

Brown, P. B. (1974) An inexpensive mechanical stimulator incorporating a new optoelectronic device. IEEE Trans. Biomed. Eng. 21: 428-429.

Chang, Y. T., J. W. Lin, and D. S. Faber (1987) Spinal inputs to the ventral dendrite of the teleost Mauthner cell. Brain Res. 417: 205213.

Diamond, J. (1971) The Mauthner cell. In Fish Physiology, Vol. 5. Sensory Systems and Electric Organs, W. S. Hoar and D. J. Randall, eds., pp. 265-346, Academic, New York.

DiDomenico, R., and R. C. Eaton (1988) Seven principles for command and the neural causation of behavior. Brain Behav. Evol. 31: 125-140.

Eaton, R. C., and R. DiDomenico (1985) Command and the neural causation of behavior: A theoretical analysis of the necessity and sufficiency paradigm. Brain Behav. Evol. 27: 132-164.

Eaton, R. C., and J. T. Hackett (1984) The role of the Mauthner cell in fast-starts involving escape in teleost fishes. In Neural Mechanisms of Startle Behavior, R. C. Eaton, ed., pp. 213-266, Plenum, New York.

Eaton, R. C., R. Bombardieri, and D. L. Meyer (1977) The Mauthnerinitiated startle response in teleost fish. J. Exp. Biol. 66: 65-81.

Eaton, K. C., W. A. Lavender, and C. M. Wieland (1981) Identification of Mauthner-initiated response patterns in goldfish: Evidence from simultaneous cinematography and electrophysiology. J. Comp. Physiol. [A] 144: 521-531.

Eaton, R. C., W. A. Lavender, and C. M. Wieland (1982) Alternative neural pathways initiate fast-start responses following lesions of the Mauthner neuron in goldfish. J. Comp. Physiol. [A] 145: 485-496.

Eaton, R. C., C. M. Wieland, and R. DiDomenico (1986) Is the Mauthner cell a Kupfermann \& Wciss command ncuron? Bchav. Brain Sci. 9: 725-727.

Faber, D. S., and H. Korn (1978) Electrophysiology of the Mauthner cell: Basic properties, synaptic mechanisms, and associated networks. In Neurobiology of the Mauthner Cell, D. S. Faber and H. Korn, eds., pp. 47-131, Raven, New York.

Faber, D. S., and H. Korn (1987) Voltage-dependence of glycineactivated $\mathrm{Cl}$ channels: A potentiometer for inhibition? J. Neurosci. 7: 807-811.

Fay, R. R. (1984) The goldfish ear codes the axis of acoustic particle motion in three dimensions. Science 225: 951-954.

Fetcho, J. R., and D. S. Faber (1988) Identification of motoneurons and interneurons in the spinal network for escapes initiated by the Mauthner cell in goldfish. J. Neurosci. (in press).

Furshpan, E. J., and T. Furukawa (1962) Intraccllular and cxtraccllular responses of the several regions of the Mauthner cell of the goldfish. J. Neurophysiol. 25: 732-771.

Hackett, J. T., and D. S. Faber (1983a) Mauthner axon networks mediating supraspinal components of the startle response. Neuroscience $8:$ 317-331.

Hackett, J. T., and D. S. Faber (1983b) Relay neurons mediate collateral inhibition of the goldfish Mauthner cell. Brain Res. 264: 302306.

Hackett, J. T., and J. L. Greenfield (1986) The behavioral role of the Mauthner neuron impulse. Behav. Brain Sci. 9: 729-730.

Howland, H. C. (1974) Optimal strategies for predator avoidance: The relative importance of speed and manoeuverability. J. Theor. Biol. 47: $333-350$.

Johnsrude, C. S., and P. W. Webb (1985) Mechanical properties of the myotomal musculo-skeletal system of the rainbow trout, Salmo gairdneri. J. Exp. Biol. 119: 71-83.

Kimmel, C. B. (1982a) Reticulospinal and vestibulospinal neurons in the young larva of a teleost fish, Brachydanio rerio. Prog. Brain Res. 57: $1-24$.

Kimmel, C. B. (1982b) Development of synapses on the Mauthner neuron. Trends Neurosci. 5: 47-50.

Korn, H., and A. Mallet (1984) Transformation of binomial input by the postsynaptic membrane at a central synapse. Science $225: 1157-$ 1159 . 
Kuypers, H. G. J. M. (1982) A new look at the organization of the motor system. In Progress in Brain Research, Vol. 57, Anatomy of Descending Pathways to the Spinal Cord, H. G. J. M. Kuypers and G. F. Martin, eds., pp. 381-403, Flsevier, Amsterdam.

Lauder, G. V. (1983) Food capture. In Fish Biomechanics, P. W. Webb and D. Weihs, eds., pp. 280-311, Praeger Publishers, New York.

Lee, M. T. (1982) Regeneration and functional reconnection of an identified vertebrate central neuron. J. Neurosci. 2: 1793-1811.

Martin, G. F., A. O. Humbertson, Jr., L. C. Laxson, W. M. Panneton, and I. Tschismadia (1979a) Spinal projections from the mesencephalic and pontine reticular formation in the North American opossum: A study using axonal transport techniques. J. Comp. Neurol. 187: 373-400.

Martin, G. F., A. O. Humbertson, Jr., L. C. Laxson, and W. M. Panneton (1979b) Evidence for direct bulbospinal projections to laminae IX, $\mathrm{X}$ and the intermediolateral cell column. Studies using axonal transport techniques in the North American opossum. Brain Res. 170 . $165-171$.

Martin, G. F., T. Cabana, A. O. Humbertson, L. C. Laxson, and W. M. Panneton (1981) Spinal projections from the medullary reticular formation of the North American opossum: Evidence for connectional heterogeneity. J. Comp. Neurol. 196: 663-682.

McClellan, A. D. (1986) Command systems for initiating locomotion in fish and amphibians: Parallels to initiation systems in mammals. In Neurobiology of Vertebrate Locomotion, S. Grillner, P. S. G. Stein, D. G. Stuart, H. Forssberg, and R. M. Herman, eds., pp. 3-20, MacMillan, London.

Metcalfe, W. K., B. Mendelson, and C. B. Kimmel (1986) Segmental homologies among reticulospinal neurons in the hindbrain of the zebrafish larva. J. Comp. Neurol. 251: 147-159.

Nissanov, J. (1987) Coordination of rapid escape turning in fishes. $\mathrm{Ph} . \mathrm{D}$. thesis, University of Colorado, Boulder.

Nissanov, J., and R. C. Eaton (1989) Reticulospinal control of rapid escape turning in fishes. Am. Zool. (in press).

Peterson, B. W. (1984) The reticulospinal system and its rolc in the control of movement. In Brain Stem Control of Spinal Cord Function, C. D. Barnes, ed., pp. 27-86, Academic, New York.

Peterson, B. W., and K. Fukushima (1982) The reticulospinal system and its role in generating vestibular and visuomotor reflexes. In Brain Stem Control of Spinal Mechanisms, B. Sjölund and A. Björklund, eds., pp. 225-251, Elsevier, New York.

Peterson, B. W., M. E. Anderson, and M. Filion (1974) Responses of pontomedullary reticular neurons to cortical, tectal and cutaneous stimuli. Exp. Brain Res. 21: 19-44.

Peterson, B. W., M. Filion, L. P. Felpel, and C. Abzug (1975) Responses of medial reticular neurons to stimulation of the vestibular nerve. Exp. Brain Res. 22: 335-350.
Peterson, B. W., N. G. Pitts, and K. Fukushima (1979) Reticulospinal connections with limb and axial motoneurons. Exp. Brain Res. 36: $1-20$.

Rock, M. K. (1980) Functional properties of Mauthner cell in the tadpole Rana catesbeiana. J. Neurophysiol. 44: 135-150.

Rock, M. K., J. T. Hackett, and D. L. Brown (1981) Does the Mauthner cell conform to the criteria of the command neuron concept? Brain Res. 204: 21-27.

Rovainen, C. M. (1967) Physiological and anatomical studies on large neurons of central nervous system of the sea lamprey (Petromyzon marinus). I. Muller and Mauthner cells. J. Neurophysiol. 30: 10001023.

Smith, J. L. (1986) Hindlimb locomotion of the spinal cat: Synergistic patterns, limb dynamics, and novel blends. In Neurobiology of Vertebrate Locomotion, S. Grillner, P. S. G. Stein, D. G. Stuart, H. Forssberg, and R. M. Herman, eds., pp. 185-199, MacMillan, London.

Sprague, J. M., and W. W. Chambers (1954) Control of posture by reticular formation and cerebellum in the intact, anesthetized and unanesthetized and in the decerebrated cat. Am. J. Physiol. 176: 5264.

Stein, P. S. G. (1978) Motor systems, with specific reference to the control of locomotion. Annu. Rev. Neurosci. 1: 61-81.

Webb, P. W. (1975) Acceleration performance of rainbow trout, Salmo gairdneri, and green sunfish, Lepomis cyanellis. J. Exp. Biol. 63: 451465 .

Webb, P. W. (1978) Fast start performance and body form in seven species of teleost fish. J. Exp. Biol. 74: 211-226.

Webb, P. W. (1982) Avoidance responses of fathead minnow to strikes by four teleost predators. J. Comp. Physiol. [A] 147: 371-378.

Webb, P. W. (1986) Effect of body form and response threshold on the vulnerability of four species of teleost prey attacked by largemouth bass (Micropterus salmoides). Can. J. Fish. Aquat. Sci. 43: 763-771.

Weihs, D. (1980) Hydrodynamics of suction feeding of fish in motion. J. Fish. Biol. 16: 425-433.

Weihs, D., and P. W. Webb (1984) Optimal avoidance and evasion tactics in predator-prey interactions. J. Theor. Biol. 106: 189-206.

Yasargil, G. M., and J. Diamond (1968) Startle-response in teleost fish: An elementary circuit for neural discrimination. Nature 220: 241-243.

Zottoli, S. J. (1977) Correlation of the startle reflex and Mauthner cell auditory responses in unrestrained goldfish. J. Exp. Biol. 66: 243254.

Zottoli, S. J., Hordes, A. R., and D. S. Faber (1987) Localization of optic tectal input to the ventral dendrite of the goldfish Mauthner cell. Brain Res. 401: 113-121. 